Taylor Rule Implementation of the Optimal Policy at the Zero Lower Bound: Does the Cost Channel Matter?

Siddhartha Chattopadhyay, Taniya Ghosh

Indira Gandhi Institute of Development Research, Mumbai June 2019 


\title{
Taylor Rule Implementation of the Optimal Policy at the Zero Lower Bound: Does the Cost Channel Matter?
}

\author{
Siddhartha Chattopadhyay, Taniya Ghosh
}

Email(corresponding author): siddhartha@hss.iitkgp.ac.in

\begin{abstract}
This paper analyzes the implementation of the optimal policies at the Zero Lower Bound (ZLB) by the Taylor rule in the presence of cost channel. We find that, the presence of cost channel significantly impairs the ability of the Taylor rule to implement optimal policies when economy is subject to the ZLB. The main findings of the paper are, (i) the Taylor rule with optimally chosen inflation target partially implements the optimal discretionary policy but cannot implement the optimal policy under commitment, and (ii) the T-only policy, which follows discretion after an optimally chosen exit date from the ZLB, is the best that can be implemented by the Taylor rule in the presence of cost channel.
\end{abstract}

Keywords: New-Keynesian Model, Cost Channel, ZLB

JEL Code: E63, E52, E58 


\title{
Taylor Rule Implementation of the Optimal Policy at the Zero Lower Bound: Does the Cost Channel Matter?
}

\author{
Siddhartha Chattopadhyay* Taniya Ghosh ${ }^{\dagger}$
}

June 24, 2019

\begin{abstract}
This paper analyzes the implementation of the optimal policies at the Zero Lower Bound (ZLB) by the Taylor rule in the presence of cost channel. We find that, the presence of cost channel significantly impairs the ability of the Taylor rule to implement optimal policies when economy is subject to the ZLB. The main findings of the paper are, (i) the Taylor rule with optimally chosen inflation target partially implements the optimal discretionary policy but cannot implement the optimal policy under commitment, and (ii) the T-only policy, which follows discretion after an optimally chosen exit date from the ZLB, is the best that can be implemented by the Taylor rule in the presence of cost channel.
\end{abstract}

Keywords: New-Keynesian Model, Cost Channel, ZLB

JEL Classification: E63, E52, E58

\footnotetext{
*Corresponding author. Department of Humanities and Social Sciences, IIT Kharagpur, India. E-mail: siddhartha@hss.iitkgp.ac.in

†Indira Gandhi Institute of Development Research, Mumbai, India. E-mail: taniya@igidr.ac.in
} 


\section{Introduction}

The textbook forward looking sticky price New-Keynesian DSGE model is the workhorse of modern monetary theory and policy. Central banks - specifically in the developed countries, use the canonical New-Keynesian model for determining policy rate and formalizing optimal policy responses. However, despite its prevalent use; the canonical model suffers from divine coincidence due to the absence of short-run trade-off between the output gap and the inflation rate. Such absence of short-run trade-off allows the monetary authority to stabilize both the output gap and the inflation rate simultaneously for the canonical model. As a result, exogenous supply shocks are often introduced to the canonical model for generating meaningful policy responses. However, inclusion of the exogenous supply shock without proper microfoundation to an otherwise canonical model has been heavily criticized in the literature.

To address this problem, Ravenna and Walsh (2006) proposed a sticky price NewKeynesian DSGE model with endogenous cost push shock. The model of Ravenna and Walsh (2006) is known as the New-Keynesian DSGE model with cost channel in the literature of monetary economics. In this model, firms borrow from financial intermediaries up-front to hire labor for producing output and repay their debt with interest later after the production takes place. As a result, the marginal cost of firms appearing in the forward looking Phillips curve of the model depends both on the output gap and the nominal interest rate. The presence of the nominal interest rate in the Phillips curve yields the short-run trade-off between the output gap and the inflation rate; required to eliminate the divine coincidence of the canonical model. Using the model of Ravenna and Walsh (2006), this paper analyzes optimal policies at the ZLB and evaluates their implementation by the Taylor rule when the economy is subject to the ZLB.

Literature has ample empirical evidences about the presence of cost channel. For example, Barth and Ramey (2001) found the evidence of the cost channel by estimating a VAR model for the US using the aggregate and also the industry level data from 19592000. Christiano, et. al. (2005) found similar results for the US too. Chowdhury, et. al. (2006) on the other hand found the presence of the cost channel by estimating a hybrid New-Keynesian Phillips curve for a group of G-8 countries. Ravenna and Walsh (2006) also found the evidence of cost channel by estimating Phillips curve with endogenous cost push shock using quarterly data of the US from 1960-2001. Moreover, the evidence of cost channel is also found by Tillmann (2008, 2009a) for the US, the UK and the Euro area while estimating a forward looking hybrid Phillips Curve for each country using a 
quarterly data from 1960-2004. ${ }^{1}$

Despite the adequate empirical evidences; theoretical research on the implications of cost channel for conducting optimal policies are indeed scanty. Ravenna and Walsh (2006) have analyzed optimal policies in the presence of a cost channel. They have shown that, the cost channel significantly changes the optimal policy response and allows the output gap and the inflation rate to fluctuate due to both the productivity shock and the demand shock. Analysis of Demirel (2013) and Ali and Anwar (2013) have underscored the importance of the cost channel by noting that, the models without cost channel significantly underestimate the welfare gains produced by the optimal policy under commitment. However, neither Ravenna and Walsh (2006) nor Demirel (2013) and Ali and Anwar (2013) have incorporated the ZLB explicitly in their policy analysis.

We have analyzed the optimal policy under discretion and commitment at the ZLB in the presence of a cost channel. We have done our analysis with a large and persistent adverse demand shock; sending the economy to the ZLB. The large and persistent demand shock used in our analysis captures the implication of the prolonged global financial crisis that started in 2007-08 and continued almost for a decade. Beside the optimal policy under discretion and commitment, we have also proposed a T-only policy for the model with cost channel and compared its outcome with others. The T-only is defined as a policy where, monetary authority optimally chooses the exit date of the economy from the ZLB but follows discretion after the exit. ${ }^{2}$

Our analysis shows that, (i) commitment outperforms discretion and produces lowest welfare loss by promising higher inflationary expectations and (ii) the exit date from the ZLB under discretion rises with the degree of the strength of the cost channel, but it falls under commitment. ${ }^{3}$ It is important to note that, the points (i) and (ii) mentioned above are interrelated. As mentioned in point (i); unlike optimal discretionary policy, monetary authority under commitment takes into account the expected output gap and the inflationary expectations while minimizing the welfare loss. The optimal choice of the expected output gap and the inflationary expectations under commitment produces

\footnotetext{
${ }^{1}$ There is evidence against the presence of cost channel as well. Rabanal (2007) estimated a DSGE model for the US using quarterly data from 1950 to 2004 through Bayesian approach and found that the demand side effect dominates the monetary transmission mechanism over the supply side effect. Later, Henzel et. al. (2009) showed that, even if the cost channel fails to generate the price puzzle for the Euro area; its presence however, can explain the initial hump in prices generated by a monetary policy tightening.

${ }^{2}$ See, Jung, et. al. (2005), Eggertson and Woodford (2003), Adam and Billi (2006, 2007) and Nakov (2008) for the analysis of optimal policy at the ZLB based on the canonical model.

${ }^{3}$ Chowdhury, et. al. (2006) and Araujo (2009) have shown that, the strength of the cost channel depends on the extent of credit market imperfections of the economy. Also see, Tillmann (2009b).
} 
extra stimulus; that rises with the degree of the strength of the cost channel. Hence, the monetary authority under commitment, with an objective of minimizing the welfare loss (the present discounted value of the square of expected output gap and inflation rate), compensates the extra stimulus by quickening the exit of the economy from the ZLB compared to discretion. ${ }^{4}$

Besides formalizing optimal policies under the cost channel, we have also analyzed their implementation by the Taylor rule at the ZLB. Following Chattopadhyay and Daniel (2018), the Taylor rule used in this paper for implementing optimal policies sets the nominal interest to zero when economy is in the ZLB, but determines the policy rate according to a standard Taylor rule after the economy permanently exits the ZLB. The relevant Taylor rule after the economy exits from the ZLB follows Taylor principle, and it also has a time varying intercept depending on the natural rate of interest. ${ }^{5}$ Moreover, the Taylor rule has contemporaneous feedback from the output gap and the inflation rate, and also has an $\mathrm{AR}(1)$ inflation target - chosen optimally by the monetary authority to implement optimal policies. ${ }^{6}$

We find that, the short-run trade-off between the output gap and the inflation rate in the presence of a cost channel produces meaningful policy responses (as obtained by Ravenna and Walsh, 2006) but at the same time it significantly impairs the ability of the Taylor rule to implement optimal policies at the ZLB. From Chattopadhyay and Daniel (2018) we have already seen that, the Taylor rule with optimally chosen inflation target can fully implement discretion, commitment and the T-only policy for the canonical model when cost channel is absent. However, we find that the identical Taylor rule in the presence of a cost channel, can partially implement the optimal discretionary policy and the T-only policy but cannot implement the optimal policy under commitment. Partial implementation of discretion and the T-only policy implies that, the Taylor rule with optimally chosen inflation target either implements the inflation rate or the output gap produced by the optimal discretionary policy. However, it cannot implement both the output gap and the inflation rate simultaneously. It is important to note here that, since optimal policy under commitment, associated with the lowest welfare loss (by construc-

\footnotetext{
${ }^{4}$ Also see, Pathberiya (2016) for similar analysis.

${ }^{5}$ The natural rate of interest on the other hand, depends on the long-run real interest rate and the demand shock. Optimal response of the monetary authority in a New-Keynesian DSGE model entails a time-varying intercept in the Taylor rule (see; Woodford, 2003).

${ }^{6}$ There are empirical evidences; supporting the hypothesis that, the actual monetary policy has operated with a time-varying inflation target in the Taylor Rule. Ireland (2007) argue that the US inflation can be explained by a New Keynesian model with a Taylor Rule only if the inflation target is allowed to vary over time. Additionally, Kozicki and Tinsley (2001), Wu and Rudebusch (2004) and Gurkaynak, Sack and Swanson (2005) provide evidence of a time-varying short-run inflation target for the US.
} 
tion) cannot be implemented; the T-only policy is the best that can be implemented in the presence of a cost channel by the Taylor rule at the ZLB.

Results stated above are obtained under perfect foresight and only with a deterministic AR(1) demand shock. Hence, a natural concern would be whether our results holds under uncertainty as well. It is worth emphasizing that, the results obtained under perfect foresight (as explained above) holds for a certain type of uncertainty rule based on rational expectations with permanent exit of the economy from the ZLB. Chattopadhyay and Daniel (2018) have proposed such a kind of uncertainty rule while analyzing optimal policies for the canonical model. The uncertainty rule proposed by them has following two important properties, (i) uncertainty in the persistence of demand shock: initially its true value is unknown to the public but people realize its actual magnitude after certain period of time, but before the economy exits the ZLB, and (ii) the incidence of ZLB is persistent but non-recursive. This implies that, the economy can permanently exit the ZLB. Our results obtained under perfect foresight hold under the uncertainty rule proposed by Chattopadhyay and Daniel (20018). On the other hand, our results does not hold under the type of uncertainty rule, which never allows the permanent exit of the economy from the ZLB, as used in Adam and Billi $(2006,2007)$ and Nakov (2008). ${ }^{7}$

The uncertainty rule proposed by Chattopadhyay and Daniel (2018) has some practical implications as well. It is evident from the history that, the incidence of ZLB episodes are indeed rare. The US was in the ZLB during the time of great depression in 1930; the incidence of ZLB recurred back again during the time of global financial crisis, which started from 2007-08 and continued more than a decade. Keeping this low probability of the ZLB incidence in mind, Chattopadhyay and Daniel (2018) proposed their uncertainty rule - with two the properties stated above, while analyzing the implementation of optimal policies by the Taylor rule for the canonical model.

Moreover, the uncertainty rule of Chattopadhyay and Daniel (2018) also produces closed form analytical solution of the model with cost channel after some tedious algebraic manipulations. However, applying the intuition of Chattopadhyay and Daniel (2018) we have seen that, the results obtained under uncertainty fully endorses the results of perfect foresight even in the presence of a cost channel. Therefore, instead of using tedious mathematical calculations, we have given simple intuitive explanations to show

\footnotetext{
${ }^{7}$ Tillmann (2009b) has analyzed the implementation of the optimal policy by Taylor rule using the model of Ravenna and Walsh (2006); without explicitly incorporating the ZLB constraint into the analysis. Tillmann (2009b) has introduced uncertainty in the slope of the Phillips curve, and in the strength of the cost channel of the model. The paper shows that, a central bank, which is more uncertain about either the slope of the Phillips curve, or the strength of the cost channel; responds less aggressively to the inflation rate while setting the nominal interest rate by the Taylor rule.
} 
the equivalence of our results obtained under perfect foresight and uncertainty. It helps us in keeping our results simple, analytically tractable and also intuitively appealing.

The rest of the paper is organized as follows. Section 2 briefly describes the model. Section 3 examines optimal policies under cost channel and section 4 analyzes their implementation by the Taylor rule. Section 5 explains the issues related to uncertainty and section 6 concludes.

\section{The Model}

We have used the model developed by Ravenna and Walsh (2006) for the analysis of optimal policy at the ZLB, and also for evaluating their implementation by the Taylor rule in the presence of a cost channel. In this model, firms borrow from financial intermediaries up-front to hire labor for producing output and repay their debt with interest later after the production takes place. As a result, the marginal cost of firms appearing in the forward looking Phillips curve of the model depends both on the output gap and the interest rate. The model of cost channel developed by Ravenna and Walsh (2006) is briefly described below.

The demand side of the model is represented by a log-linearized IS curve given in equation (1) below,

$$
E_{t}\left(y_{t+1}\right)=y_{t}+\sigma\left[i_{t}-r_{t}^{n}-\pi_{t+1}\right]
$$

The equation (1) is obtained by log-linearizing individual's Euler equation around zero inflationary steady state. Here, the output gap and the inflation rate are denoted by $y_{t}$ and $\pi_{t}$ respectively. The nominal interest rate and the natural rate of interest are denoted by $i_{t}$ and $r_{t}^{n}$ respectively. The natural rate of interest is calculated as, $r_{t}^{n}=i-\sigma^{-1} u_{t}$, where $i=\beta^{-1}-1$ is the long-run interest rate and $\sigma \geq 0$ is the elasticity of substitution. The demand shock is denoted by $u_{t}$. We have assumed that, the demand shock follows a deterministic $\operatorname{AR}(1)$ process with persistence, $\rho$ as given in equation (2) below. ${ }^{8}$

$$
u_{t}=\rho^{t-1} u_{1}, 0<\rho<1
$$

The supply side of the economy, on the other hand is represented by a forward looking

\footnotetext{
${ }^{8}$ Demand shock is the combination of shocks associated with preferences, technology, fiscal policy, etc. A large adverse demand shock yields negative natural rate of interest and sends the economy to the liquidity trap. The dynamics of the demand shock is taken from Jung, et. al. (2005).
} 
Phillips curve given in equation (3).

$$
\pi_{t}=\beta E_{t}\left(\pi_{t+1}\right)+\kappa\left(\sigma^{-1}+\eta\right) y_{t}+\kappa \delta\left(i_{t}-i\right)
$$

where, $\eta$ is the inverse of elasticity of the Frisch labor supply curve and $\kappa=\frac{(1-s)(1-s \beta)}{s}$ is the slope of the Phillips curve with $(1-s)$ representing the fraction of firms allowed to choose their price optimally each period by the Calvo fairy. The Phillips curve given in equation (3) differs from the Phillips curve of the canonical model due to the presence of an endogenous cost push shock; given by the term, $\kappa \delta\left(i_{t}-i\right)$. Here, $\delta>0$ determines the strength of the cost channel, and also the degree of interest rate pass through of the economy. Ravenna and Walsh (2006) have used $\delta=1$ while analyzing optimal policies in the presence of a cost channel. ${ }^{9}$

To understand the implication of the endogenous cost push shock note that, the changes in the nominal interest rate has both direct and indirect effect on the inflation rate for a model with cost channel. An unit rise of nominal interest rate causes the inflation rate to rise by $\kappa \delta$ unit from the Phillips curve - this is the direct effect of nominal interest rate on the inflation rate. On the other hand, identical rise in nominal interest rate reduces the output gap by $\sigma$ unit from the IS equation, which in turn reduces the inflation rate by $\frac{\left(\sigma^{-1}+\eta\right)}{\sigma^{-1}}$ unit from the Phillips curve - this is the indirect effect of the nominal interest rate on the inflation rate. The indirect effect of the nominal interest rate dominates its direct effect when $\delta<\frac{\left(\sigma^{-1}+\eta\right)}{\sigma^{-1}}$. Note, a contractionary monetary policy represented by an increase in nominal interest rate reduces the inflation rate in this model when the indirect effect of nominal interest rate dominates its direct effect and vice-versa. ${ }^{10}$ Ravenna and Walsh (2006) sets, $\delta \in\left[1, \frac{\sigma^{-1}+\eta}{\sigma^{-1}}\right)$ so that the model can produce the standard short-run negative relationship between the nominal interest rate and the inflation rate. We have seen that, $\delta \in\left[1, \frac{\sigma^{-1}+\eta}{\sigma^{-1}}\right)$ also produces a sunspot free determinate equilibrium under optimal discretionary policy in the presence of ZLB, as explained in Section 3.

\footnotetext{
${ }^{9}$ Chowdhury et. al., (2006) and Araujo (2009) have done their analysis in the presence of a credit market imperfection; with $\delta>1$. Note that, we get the New-Keynesian Phillips curve of the canonical model back when cost channel is absent $(\delta=0)$.

${ }^{10}$ Note, the direct effect of nominal interest rate dominates its indirect effect when, $\delta>\frac{\left(\sigma^{-1}+\eta\right)}{\sigma^{-1}}$. In this case, a rise in nominal interest rate increases inflation rate, and the model yields price puzzle - producing positive relationship between the nominal interest rate and the inflation rate.
} 


\subsection{The Loss Function}

We complete the description of the model by defining a loss function for the monetary authority. Here, the objective of the monetary authority is to minimize the welfare loss by optimally choosing a time path of the output gap, the inflation rate and the nominal interest rate simultaneously. Ravenna and Walsh (2006) have derived the loss function in the presence of a cost channel by a second order Taylor series approximation of the individual utility function around a zero inflationary steady state. The loss functions derived by Ravenna and Walsh (2006) is given below, ${ }^{11}$

$$
\frac{1}{2} E_{0} \sum_{t=1}^{\infty} \beta^{t-1}\left(\pi_{t}^{2}+\lambda y_{t}^{2}\right), \lambda \in[0, \infty)
$$

where, $\lambda=\frac{\kappa\left(\sigma^{-1}+\eta\right)}{\theta}$ is the weight given to the output gap relative to the inflation rate and $\theta>1$ is the own price elasticity of output.

\section{Optimal Policy at the ZLB}

To analyze the optimal policies at the ZLB in the presence of a cost channel; we assume that an adverse demand shock hits the economy in period 1. Also assume that the shock is large enough that yields a negative natural rate of interest, i.e., $r_{t}^{n}=i-\sigma^{-1} u_{t}<0$ for $t=1$. Since, the demand shock follows a deterministic $\operatorname{AR}(1)$ process with persistence, $0<\rho<1$, the natural rate of interest becomes positive in due course as soon as the magnitude of demand shock falls below $\sigma i$. We assume that, the economy is in the ZLB for $t=1,2, \ldots, T$ and exits the ZLB permanently at $t=T+1$. Given this backdrop, the objective of the monetary authority is to find the optimal time path of the output gap, the inflation rate, the nominal interest rate and the exit date from the ZLB under discretion and commitment.

\subsection{Optimal Policy under Discretion}

Monetary authority under discretion minimizes the loss function given in equation (4) subject to the IS equation (given in equation (1)), the Phillips curve (given in equation

\footnotetext{
${ }^{11}$ Ravenna and Walsh (2006) have assumed that, a fraction; $\left(1-\gamma_{t}\right)$ of the output is consumed by government. As a result, the loss function in their paper depends on $\gamma_{t}$; determining the impact of fiscal policy in the analysis of optimal monetary policy. Our paper does not have government expenditure. Therefore, we have $\gamma_{t}=0$ for all $t$ - producing the loss function given in equation (4) in the text.
} 
(3)) and the feasibility constraint, $i_{t} \geq 0$ given the future expectations of the output gap and the inflation rate. The relevant Lagrangian under perfect foresight with Lagrange multipliers, $\phi_{1, t}, \phi_{2, t}, \phi_{3, t}$ associated respectively with the IS equation, the Phillips curve and the feasibility constraint for deriving optimal discretionary policy is,

$$
\mathcal{L}_{D}=\left\{\sum_{t=1}^{\infty} \beta^{t-1}\left[\begin{array}{c}
-\frac{1}{2}\left(\pi_{t}^{2}+\lambda y_{t}^{2}\right)-\phi_{1, t}\left[\sigma\left(i_{t}-\pi_{t+1}-r_{t}^{n}\right)-y_{t+1}+y_{t}\right] \\
-\phi_{2, t}\left[\pi_{t}-\kappa\left(\sigma^{-1}+\eta\right) y_{t}-\kappa \delta\left(i_{t}-i\right)-\beta \pi_{t+1}\right]+\phi_{3, t} i_{t}
\end{array}\right]\right\}
$$

The First Order Conditions are,

$$
\begin{aligned}
\frac{\partial L}{\partial \pi_{t}} & =-\pi_{t}-\phi_{2, t}=0 \\
\frac{\partial L}{\partial y_{t}} & =-\lambda y_{t}-\phi_{1, t}+\kappa\left(\sigma^{-1}+\eta\right) \phi_{2, t}=0 \\
\frac{\partial L}{\partial \phi_{1, t}} & =\sigma\left(i_{t}-\pi_{t+1}-r_{t}^{n}\right)-y_{t+1}+y_{t}=0 \\
\frac{\partial L}{\partial \phi_{2, t}} & =\pi_{t}-\kappa\left(\sigma^{-1}+\eta\right) y_{t}-\kappa \delta\left(i_{t}-i\right)-\beta \pi_{t+1}=0 \\
\frac{\partial L}{\partial i_{t}} & =-\sigma \phi_{1, t}+\kappa \delta \phi_{2, t}+\phi_{3, t}=0 \\
\phi_{3, t} \frac{\partial L}{\partial \phi_{3, t}} & =\phi_{3, t} i_{t}=0, \phi_{3, t} \geq 0, i_{t} \geq 0 \text { with complementary slackness }
\end{aligned}
$$

Equations (5) and (6) gives,

$$
\phi_{1, t}=-\left(\lambda y_{t}+\kappa\left(\sigma^{-1}+\eta\right) \pi_{t}\right)
$$

and using equations (5), (9), and (11), equation (10) can be written as,

$$
\phi_{3, t}=Q_{t}^{d}=\kappa\left(\delta-\sigma\left(\sigma^{-1}+\eta\right)\right) \pi_{t}-\sigma \lambda y_{t}
$$

Note, the complementary slackness condition given in equation (10) implies,

$$
\begin{aligned}
& i_{t}=0 \text { when, } Q_{t}^{d}>0 \\
& i_{t}>0 \text { when, } Q_{t}^{d}=0
\end{aligned}
$$

The economy is in the ZLB as long as, $Q_{t}^{d}>0$ and the economy permanently exits the ZLB when, $Q_{t}^{d}=0$. We assume that, the economy is in the ZLB for the period, $1,2,3, \ldots, T^{d}$ and exits ZLB permanently at $T^{d}+1$ under discretion. As a result, we have $i_{t}=0$ for 
$t=1,2, \ldots, T^{d}$ and $i_{t}>0$ for $T^{d}+1$ onwards. Our objective is to find the optimal exit date and the corresponding output gap, inflation rate and nominal interest rate.

\subsubsection{Post-Exit Solution}

We have assumed that, the economy exits the ZLB permanently at $T^{d}+1$. Hence, we get $i_{t}>0$ and $\phi_{3, t}=0$, for $t=T^{d}+1, T^{d}+2, T^{d}+3, .$. Solving equations (5), (6) and (9) with $\phi_{3, t}=0$ gives,

$$
\pi_{t}=-\chi y_{t}
$$

where,

$$
\chi=\frac{\lambda}{\kappa\left[\sigma^{-1}(1-\delta)+\eta\right]}>0
$$

We get post-exit output gap and inflation rate under discretion by solving equations (7), (8) and (14) simultaneously. ${ }^{12}$

Equations (7) and (8) gives,

$$
y_{t+1}+\sigma\left(1+\frac{\beta}{\kappa \delta}\right) \pi_{t+1}=\left[1-\frac{\sigma^{-1}+\eta}{\sigma^{-1} \delta}\right] y_{t}+\frac{\sigma}{\kappa \delta} \pi_{t}+u_{t}
$$

and substituting equation (15) in equation (14) gives,

$$
y_{t+1}=\mu y_{t}-\frac{u_{t}}{\sigma \chi\left(1+\frac{\beta}{\kappa \delta}\right)-1}
$$

where,

$$
\mu=\frac{\frac{\sigma}{\kappa \delta}\left(\chi+\kappa\left(\sigma^{-1}+\eta\right)\right)-1}{\sigma \chi\left(1+\frac{\beta}{\kappa \delta}\right)-1}
$$

Note, we need $\mu>1$ to solve equation (16) forward. We have seen that, $\mu$ and $\delta$ has negative relationship and $\delta \in\left[1, \frac{\sigma^{-1}+\eta}{\sigma^{-1}}\right)$ yields $\mu>1 .{ }^{13}$ Forward solution of equation (16) with $\mu>1$ gives,

$$
y_{t}=\frac{u_{t}}{\left[\sigma \chi\left(1+\frac{\beta}{\kappa \delta}\right)-1\right](\mu-\rho)}, \text { for } t=T^{d}+1, T^{d}+2, \ldots
$$

Substituting, equation (17) to equation (14) gives the corresponding post-exit inflation

\footnotetext{
${ }^{12}$ Note that, the equation (14) has the short-run trade-off between the output gap and the inflation rate due to cost channel, which eliminates the divine coincidence.

${ }^{13}$ Ravenna and Walsh (2006), Chowdhury et. al. (2006) and Tillman (2007) have estimated $\delta \in[1,1.4]$. We get $\mu>1$, when $\delta \in[1,1.8]$.
} 
rate,

$$
\pi_{t}=-\frac{\chi u_{t}}{\left[\sigma \chi\left(1+\frac{\beta}{\kappa \delta}\right)-1\right](\mu-\rho)}
$$

The post-exit output gap and inflation rate gives,

$$
Z_{T^{d}+1}=\left[\begin{array}{l}
y_{T^{d}+1} \\
\pi_{T^{d}+1}
\end{array}\right]
$$

Next, we calculate $Z_{t}$ for $t=1,2, \ldots, T^{d}$ given the terminal condition $Z_{T^{d}+1}$ numerically from equation (19). $T^{d}$ is determined as the time period when, $Q_{T^{d}}^{d}>0$ for the last time or $Q_{T^{d}+1}^{d}=0$ for the first time. The nominal interest rate, $i_{t}=0$ for $t=1,2, \ldots, T^{d}$ and $i_{t}>0$ for $t=T^{d}+1, T^{d}+2, \ldots$. The post-exit nominal interest rate is calculated from the IS equation.

\subsubsection{Pre-Exit Solution}

Equations (1) and (3) with $i_{t}=0$ gives,

$$
Z_{t+1}=c+A Z_{t}-a r_{t}^{n}
$$

where,

$$
\begin{aligned}
& c=\left[\begin{array}{c}
-\frac{\sigma \kappa \delta i}{\beta} \\
\frac{\kappa \delta i}{\beta}
\end{array}\right], a=\left[\begin{array}{l}
\sigma \\
0
\end{array}\right], Z_{t}=\left[\begin{array}{l}
y_{t} \\
\pi_{t}
\end{array}\right], \\
& A=\left[\begin{array}{cc}
1+\frac{\sigma \kappa\left(\sigma^{-1}+\eta\right)}{\beta} & -\frac{\sigma}{\beta} \\
-\frac{\kappa\left(\sigma^{-1}+\eta\right)}{\beta} & \frac{1}{\beta}
\end{array}\right]
\end{aligned}
$$

Solving equation (20) forward gives,

$$
Z_{t}=\Gamma_{t}^{d}+A^{-\left(T^{d}-t+1\right)} Z_{T^{d}+1}
$$

where,

$$
\Gamma_{t}^{d}=\sum_{k=t}^{T^{d}} A^{-(k-t+1)} a r_{k}^{n}-\sum_{k=t}^{T^{d}} A^{-(k-t+1)} c
$$

and $Z_{T^{d}+1}$ is given in equation (19). ${ }^{14}$

\footnotetext{
${ }^{14}$ Note that, the output gap given in equation (16) is a jump variable and it is associated with a sunspot under uncertainty. Therefore, we need, $\mu>1$ or, $\delta \in\left[1, \frac{\sigma^{-1}+\eta}{\sigma^{-1}}\right)$ to produce a sunspot free determinant
} 
Figure 1 plots the output gap, the inflation rate, the nominal interest rate and the real interest rate under discretion for $\delta=1$ and 1.5. Moreover, to capture the prolonged ZLB episodes as observed during the decade-long global financial crisis; we have taken, $u_{1}=0.024$ and $\rho=0.9$ to generate Figure 1. Other parameters used to generate Figure 1 are reported in Table 1 below.

\begin{tabular}{|cccc|}
\hline Parameter & Description & Value $^{\text {Source }}$ & Sour $^{15}$ \\
$\sigma$ & logarithmic preference & 1 & AB (2006) \\
$\kappa$ & discount factor & 0.99 & Standard \\
$\eta$ & measure of price stickiness & 0.028 & AB (2006) \\
$\lambda$ & relative weight on the output gap in loss function & 0.0074 & AB (2006) \\
$\delta$ & cost channel & 1 and 1.5 & \\
\hline \hline \multicolumn{4}{c}{ Table 1: Parameter Values } \\
\hline
\end{tabular}

To explain the dynamics under optimal discretionary policy note that, the economy tries to accommodates the adverse demand shock by reducing the nominal interest rate at the first place. However, it fails to accommodate it fully when the demand shock is large enough - causing recession and deflation. It also sends the nominal interest rate to the ZLB, as portrayed in Figure 1 below. Figure 1 also shows that, the severity of recession and the deflation in the presence of a cost channel rises with the degree of the strength of the cost channel - determined by $\delta .^{16}$

equilibrium under ratioal expectations. Solution of the output gap and the inflation rate under rational expectations are identical with equations (16) and (14) respectively - representing the post-exit output gap and the inflation rate under perfect foresight (see, section 5 for detail).

${ }^{15} \mathrm{AB}$ and RW in Table 1 imply Adam and Billi and Ravenna and Walsh respectively.

${ }^{16}$ Note, the strength of the cost channel can also be interpreted as the degree of interest rate pass through in this paper. 
Figure 1: Optimal Policy under Discretion
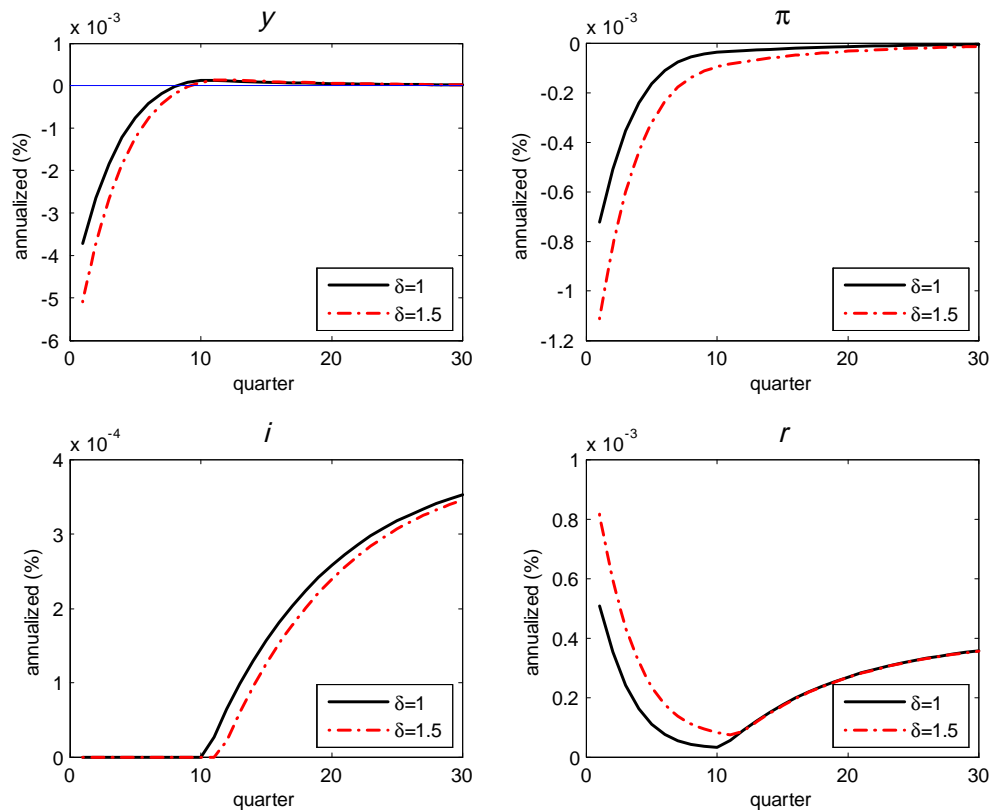

The severity of recession and deflation rises with the strength of the cost channel; inducing the exit date of the economy from the

ZLB to rise for minimizing the welfare loss under discretion.

Along with this, Figure 1 also shows that the exit date of the economy from the ZLB rises with $\delta$ under the optimal discretionary policy in the presence of a cost channel. To understand the relationship between the exit date and the degree of the strength of the cost channel under discretion note that, the coefficient matrix $A$ given in equation (21), which governs the dynamics of the system under discretion has two eigenvalues - one less than one and another is greater than one in magnitude, under the reasonable parameterization given in Table 1. The presence of an unstable eigenvalue with magnitude greater than one gives extra stimulus to the system as the exit date rises. As a result, when the extent of recession and deflation rises with the degree of the strength of the cost channel; the system postpones the exit date of the economy from the ZLB, and accordingly generates additional stimulus to minimize the welfare loss. The additional stimulus obtained by delaying the exit date of the economy from the ZLB is optimally determined by equation (12).

Moreover, it is also worth mentioning here that, the exit date of the economy from the 
ZLB in a model with cost channel not only depends on the time path of the natural rate of interest but also on the non-zero output gap and inflation rate given by $Z_{T^{d}+1}$. As a result, unlike the canonical model, the exit date of the economy from the ZLB under the optimal discretionary policy is endogenous and not governed entirely by the dynamics of the natural rate of interest in the presence of a cost channel. ${ }^{17}$

\subsection{Optimal Policy under Commitment}

This section analyzes the optimal policy under commitment in the presence of a cost channel. Here, the objective of the monetary authority is to minimize equation (4) by optimally choosing the output gap, the inflation rate and the nominal interest rate, subject to the IS equation (given in equation (1)), the Phillips curve (given in equation (3)) and the feasibility constraint, $i_{t} \geq 0$. Moreover, unlike discretion, monetary authority under commitment also takes into account societal expectations while minimizing the welfare loss. The relevant Lagrangian under perfect foresight with Lagrange multipliers, $\phi_{1, t}, \phi_{2, t}, \phi_{3, t}$ associated respectively with the IS equation, the Phillips curve and the feasibility constraint is given below,

$$
\mathcal{L}_{C}=\sum_{t=1}^{\infty} \beta^{t-1}\left\{\begin{array}{c}
-\frac{1}{2}\left[\pi_{t}^{2}+\lambda y_{t}^{2}\right]-\phi_{1, t}\left[\sigma\left(i_{t}-\pi_{t+1}-r_{t}^{n}\right)-y_{t+1}+y_{t}\right] \\
-\phi_{2, t}\left[\pi_{t}-\kappa\left(\sigma^{-1}+\eta\right) y_{t}-\kappa \delta\left(i_{t}-i\right)-\beta \pi_{t+1}\right] \\
+\phi_{3, t} i_{t}
\end{array}\right\}
$$

\footnotetext{
${ }^{17}$ In the canonical model, $Z_{T^{d}+1}=0$. Therefore, the exit date of the economy from the ZLB under discretion is exogenous for the canonical model, and it is determined completely by the time path of the natural rate. As a result, the economy in the canonical model exits the ZLB as soon as the natural rate of interest becomes positive under the canonical model (see, Jung, et. al., 2005 for detail).
} 
The First Order Conditions are,

$$
\begin{aligned}
\frac{\partial L}{\partial \pi_{t}} & =-\pi_{t}-\phi_{2, t}+\sigma \beta^{-1} \phi_{1, t-1}+\phi_{2, t-1}=0 \\
\frac{\partial L}{\partial y_{t}} & =-\lambda y_{t}-\phi_{1, t}+\kappa\left(\sigma^{-1}+\eta\right) \phi_{2, t}+\beta^{-1} \phi_{1, t-1}=0 \\
\frac{\partial L}{\partial \phi_{1, t}} & =\sigma\left(i_{t}-\pi_{t+1}-r_{t}^{n}\right)-y_{t+1}+y_{t}=0 \\
\frac{\partial L}{\partial \phi_{2, t}} & =\pi_{t}-\kappa\left(\sigma^{-1}+\eta\right) y_{t}-\kappa \delta\left(i_{t}-i\right)-\beta \pi_{t+1}=0 \\
\frac{\partial L}{\partial i_{t}} & =-\sigma \phi_{1, t}+\kappa \delta \phi_{2, t}+\phi_{3, t}=0 \\
\phi_{3, t} \frac{\partial L}{\partial \phi_{3, t}} & =\phi_{3, t} i_{t}=0, \phi_{3, t} \geq 0, i_{t} \geq 0 \text { with complementary slackness }
\end{aligned}
$$

Note, equation (26) gives,

$$
\phi_{3, t}=Q_{t}^{c}=\sigma \phi_{1, t}-\kappa \delta \phi_{2, t} \geq 0
$$

Also note that, the complementary slackness condition given in equation (27) implies,

$$
\begin{aligned}
& i_{t}=0 \text { when, } Q_{t}^{c}>0 \\
& i_{t}>0 \text { when, } Q_{t}^{c}=0
\end{aligned}
$$

The economy is in the ZLB as long as, $Q_{t}^{c}>0$ and permanently exits the ZLB when, $Q_{t}^{c}=0$. We assume that, the economy is in the ZLB for the period, $1,2,3, \ldots, T^{c}$ and exits the ZLB permanently at $T^{c}+1$. As a result, $i_{t}=0$ for $t=1,2, \ldots, T^{c}$ and $i_{t}>0$ for $T^{c}+1$ onwards. Our objective is to calculate the optimal exit date and the corresponding output gap, inflation rate, nominal interest rate and real interest rate.

\subsubsection{Post-Exit Solution}

The solution of the post-exit output gap, the inflation rate and the exit date from the ZLB under commitment is given in the appendix. Appendix shows that, unlike discretion, the post-exit output gap and inflation rate under commitment also has an endogenous persistence - determined by the stable eigenvalue, $0<\omega_{2}<1$ of the coefficient matrix $B$, along with the exogenous persistence - determined by the persistence of the demand shock, $\rho$. The IS equation solves the nominal interest rate once the post-exit output gap and inflation rate is solved. The solution of the post-exit output gap and inflation rate 
yields the vector, $Z_{T^{c}+1}=\left[\begin{array}{ll}y_{T^{c}+1} & \pi_{T^{c}+1}\end{array}\right]^{\prime}$ - required for solving the output gap and the inflation rate when the economy is in the ZLB.

\subsubsection{Pre-Exit Solution}

Note, equations (24) and (25) with $i_{t}=0$ gives,

$$
Z_{t+1}=c+A Z_{t}-a r_{t}^{n}
$$

Solving equation (30) forward gives,

$$
Z_{t}=\Gamma_{t}^{c}+A^{-\left(T^{c}-t+1\right)} Z_{T^{c}+1}
$$

where,

$$
\Gamma_{t}^{c}=\sum_{k=t}^{T^{c}} A^{-(k-t+1)} a r_{k}^{n}-\sum_{k=t}^{T^{c}} A^{-(k-t+1)} c
$$

Equation (30) gives the output gap and the inflation rate under commitment when economy is in the ZLB, given $Z_{T^{c}+1}$.

Figure 2 portrays the output gap, the inflation rate, the nominal interest rate and the real interest rate under commitment for the parameter values given in Table 1 and the demand shock with, $u_{1}=0.024$ and $\rho=0.9$. 
Figure 2: Optimal Policy under Commitment
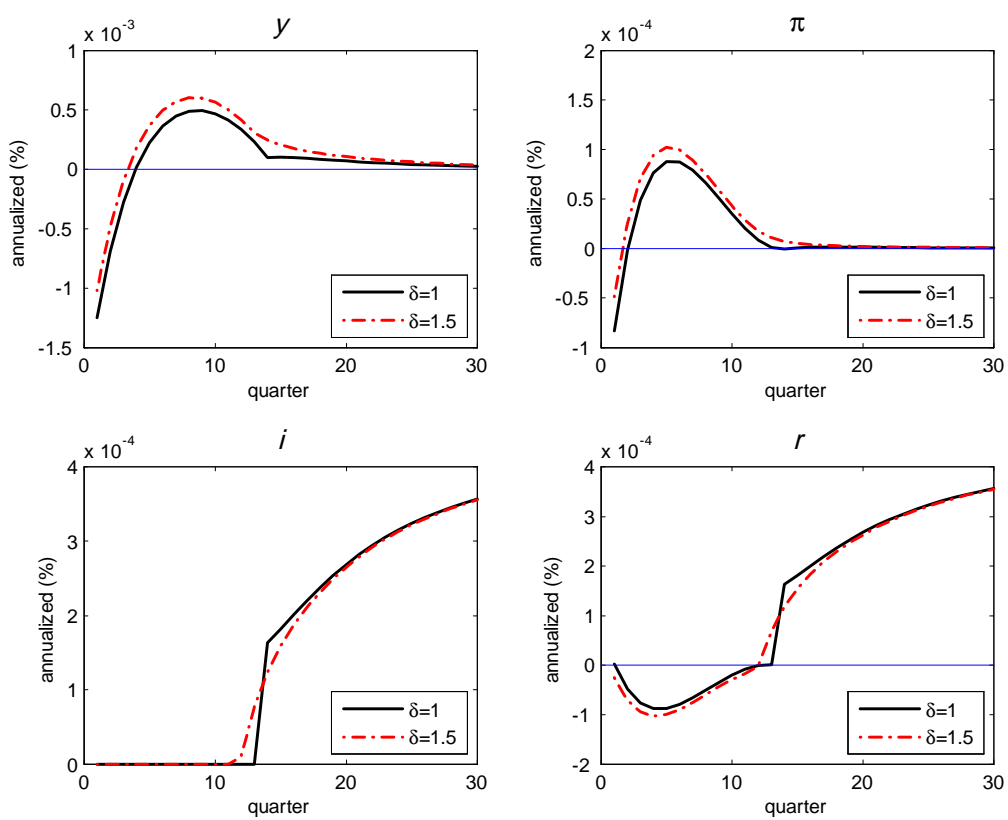

Promise of future inflation and boom produces additional stimulus. The stimulus rises with the strength of the cost channel; inducing the exit date of the economy from the ZLB to fall for minimizing the welfare loss under commitment.

Figure 2 shows that, the commitment promises future boom and inflation, which gives extra stimulus to the system. We find that, the stimulus under commitment rises with the degree of the strength of the cost channel, $\delta$. Therefore, as $\delta$ rises the system reduces the exit date of the economy from the ZLB optimally to minimize the welfare loss by controlling the dynamics of the output gap and the inflation rate. ${ }^{18}$

\section{Implementation of Optimal Policies by the Taylor Rule}

This section analyzes the implementation of optimal policies under discretion and commitment by the Taylor rule. Following Chattopadhyay and Daniel (2018), we have used a Taylor rule for our analysis that follows Taylor principle, and also has contemporaneous

${ }^{18}$ Also see; Pathberiya (2016) for detail. 
feedback of the inflation rate and the output gap. The Taylor rule used in our analysis is given in equation (31).

$$
i_{t}=\max \left(0, r_{t}^{n}+\pi_{t+1}^{*}+\phi_{\pi}\left(\pi_{t}-\pi_{t}^{*}\right)+\phi_{y}\left(y_{t}-y_{t}^{*}\right)\right)
$$

The (truncated) Taylor rule given in equation (31) sets the nominal interest to zero when the economy is in the ZLB. However, the nominal interest rate is determined by equation (32) when economy is out of the ZLB.

$$
i_{t}=r_{t}^{n}+\pi_{t+1}^{*}+\phi_{\pi}\left(\pi_{t}-\pi_{t}^{*}\right)+\phi_{y}\left(y_{t}-y_{t}^{*}\right)
$$

where, $\pi_{t}^{*}$ is the time-varying inflation target.

We set inflation target to zero when economy is in the ZLB. However, the inflation target follows a deterministic $\mathrm{AR}(1)$ process after economy exits the ZLB. If $T+1$ is the exit date of the economy from the ZLB for a generic optimal policy scheme; the inflation target process is given by,

$$
\pi_{t}^{*}=\xi^{t-(T+1)} \pi_{T+1}^{*}, \quad t \geq T+1 \ldots
$$

We have also set, $\phi_{\pi}>1$ and $0<\phi_{y}<1$, so that the Taylor principle given in equation (34) is satisfied. ${ }^{19}$

$$
\phi_{\pi}+\frac{1-(\beta+\kappa \delta)}{\kappa\left(\sigma^{-1}+\eta\right)} \phi_{y}>1
$$

Solving equations (1), (3) and (32) simultaneously gives the output gap and the inflation rate for $t \geq T+1$, when nominal interest rate is positive, i.e., when economy exits the ZLB. Derivation of the output gap and the inflation rate under Taylor rule after the economy permanently exits the ZLB is given respectively in equation (35) and (36) below, ${ }^{20}$

$$
\begin{aligned}
& y_{t}=\chi_{y_{1}} z \pi_{t}^{*}+\chi_{y_{2}} u_{t}, t \geq T+1 \ldots \\
& \pi_{t}=\chi_{\pi_{1}} z \pi_{t}^{*}+\chi_{\pi_{2}} u_{t}, t \geq T+1 \ldots
\end{aligned}
$$

\footnotetext{
${ }^{19}$ See appendix for the derivation of equation (34).

${ }^{20}$ See appendix for the derivation of equation (35) and (36).
} 


\subsection{Implementation of the Optimal Discretionary Policy}

This section analyzes the implementation of the optimal discretionary policy by the Taylor rule given in equation (31). Note, when economy is in the ZLB; we calculate the output gap and the inflation rate by solving equations (1), (3) and (31) simultaneously by setting $i_{t}=0$. Therefore, the output gap and the inflation rate produced by the (truncated) Taylor rule are identical with equation (21) - representing the output gap and the inflation rate obtained under discretion when economy is in the ZLB. As a result, to implement optimal discretionary policy by the Taylor rule; our objective is to simply calculate an inflation target such that the output gap and the inflation rate obtained under Taylor rule matches with the same produced by discretion after the economy permanently exits the ZLB. In other words, our objective here is to find a $\pi_{t}^{*}$ such that, the set of equations (35), (36) and equations (17) and (18) produces identical solution of $y_{t}$ and $\pi_{t}$ for $t \geq T^{d}+1$, where $T^{d}+1$ is the exit date of the economy from the ZLB under discretion. The implementation of the optimal discretionary policy by Taylor rule is discussed in Theorem 1 below.

Theorem 1: In the presence of a cost channel, the Taylor rule, (i) with time varying intercept determined by the natural rate of interest and a deterministic AR(1) inflation target, (ii) having contemporaneous feedback from the output gap and the inflation rate, and (iii) following the Taylor principle, partially implements the optimal discretionary policy at the zero lower bound by choosing the inflation target optimally.

Proof: The Taylor rule given in equation (31) implements the optimal discretionary policy if there exists a $\pi_{t}^{*}$ such that the ratio of the equations (36) and (35) evaluated at, $\pi_{t}^{*}=-\chi$ - the ratio of the equations (18) and (17). Therefore, to implement optimal discretionary policy by Taylor rule given in equation (31), we calculate an inflation target by equating equations (18) and (36), as given below.

$$
\pi_{t}^{*}=-\left[\frac{\frac{\chi u_{t}}{\left[\sigma \chi\left(1+\frac{\beta}{\kappa \delta}\right)-1\right](\mu-\rho)}+\chi_{\pi_{2}}}{\chi_{\pi_{1}} z}\right] u_{t}, t \geq T^{d}+1
$$

The inflation target given in equation (37) matches the inflation rate of discretion with the Taylor rule. Subsequently, substituting equation (37) in equation (35) gives us the output gap consistent with the inflation target given in equation (37). We find that, the ratio of the inflation rate and the output gap evaluated at $\pi_{t}^{*}$ produced by the Taylor rule is not equals to, $-\chi$ - the ratio of the post-exit inflation rate and the output gap obtained under discretion. Therefore, we find that the Taylor rule given in equation (31) with 
optimally chosen $\mathrm{AR}(1)$ inflation target partially implements the optimal discretionary in the presence of a cost channel.

It is important to note that, the Taylor rule given in equation (31) can implement optimal discretionary policy either by matching the output gap or the inflation rate. However, since the inflation rate receives higher weight relative to the output gap in the loss function; matching the inflation rate (instead of the output gap) is optimal - as it always produces the lowest welfare loss.

Figure 3 shows how closely the Taylor rule given in equation (31) implements the optimal discretionary policy by matching the inflation rate. Figure 3 is generated by setting, $\phi_{\pi}=1.5, \phi_{y}=0.5, \delta=1, u_{1}=0.024, \rho=0.9$ along with other parameter values reported in Table 1. Figure 3 identifies small difference in nominal interest rate due to marginal difference in the (post-exit) output gap between optimal discretionary policy implemented by the Taylor rule through matching inflation rate and the optimal discretionary policy itself.

Figure 3: Implementing Optimal Discretionary Policy by Taylor Rule
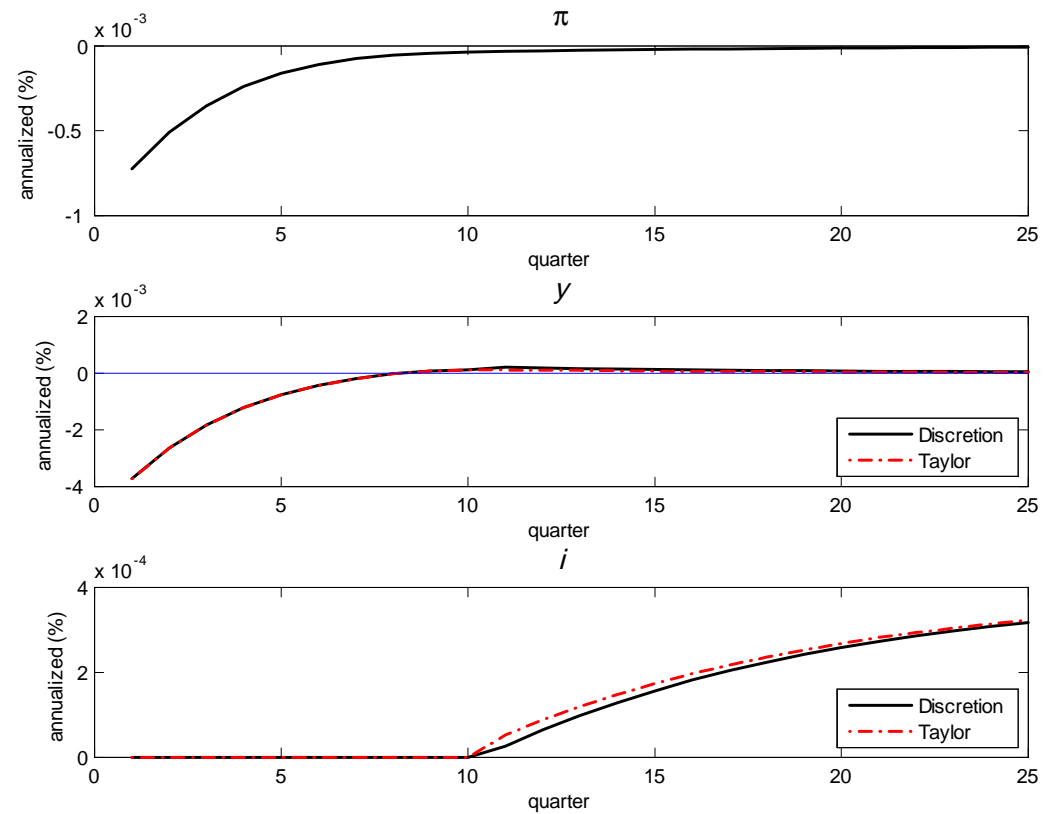

Optimal discretionary policy implemented by Taylor rule by matching the inflation rate closely replicates the optimal policy under discretion itself, and produces almost identical welfare gains. 
By comparing the welfare loss between the optimal discretionary policy implemented by the Taylor rule through matching inflation rate and the optimal discretionary policy itself, we find that the welfare loss under the optimal discretionary policy implemented by the Taylor rule through matching the inflation rate is only 1.00074 times higher than that of the optimal discretionary policy. This implies that, the optimal discretionary policy implemented by the Taylor rule through matching the inflation rate closely replicates the optimal discretionary policy in the presence of a cost channel.

\subsection{Implementation of the Optimal Policy under Commitment}

We have already seen that, the Taylor rule with $\mathrm{AR}(1)$ inflation target given in equation (31) partially implements discretion in the presence of a cost channel. Here, we show that the same Taylor rule cannot implement the optimal policy under commitment in the presence of a cost channel.

The output gap and the inflation rate under commitment, as shown in Appendix 7.1 and 7.2 is no longer an $\operatorname{AR}(1)$ process in the presence of a cost channel; after the economy permanently exits the ZLB. As a result, the post-exit output gap and inflation rate under commitment has an endogenous persistence, determined by the stable root of the system, $\omega_{2}$ along with an exogenous persistence, determined by the persistence of the demand shock, $\rho$ as given in equations (48), (43) and (44). Since the post-exit output gap and inflation rate is not an $\mathrm{AR}(1)$ process anymore, a Taylor rule with $\mathrm{AR}(1)$ inflation target cannot implement them by choosing $\mathrm{AR}(1)$ inflation target optimally. The above discussion regarding the implementation of the optimal policy under commitment by the Taylor rule yields the second theorem of our paper.

Theorem 2: In the presence of a cost channel, the Taylor rule with identical characteristics stated in Theorem 1 cannot implement the optimal policy under commitment by an optimally chosen $A R(1)$ inflation target at the zero lower bound.

Proof: Solving $\phi_{1, t}$ from equation (48) given in the appendix we get,

$$
\phi_{1, T+j}=\omega_{2}^{j-1} \phi_{1, T^{c}}+\frac{\rho^{j}\left[1-\left(\frac{\omega_{2}}{\rho}\right)^{j+1}\right]}{\left(\omega_{1}-\rho\right)(\tau+\alpha)\left(1-\frac{\omega_{2}}{\rho}\right)} u_{T^{c}+1}
$$

We get the inflation rate under commitment after the economy permanently exits the ZLB by substituting equation (38) in equation (43). The post-exit inflation rate under 
commitment is given below,

$$
\pi_{T+j}=m_{1} \omega_{2}^{j-1} \phi_{1, T^{c}}+\left[m_{2} \rho^{j-1}-m_{3}\left(\frac{\omega_{2}}{\rho}\right)^{j}\right] u_{T^{c}+1}, j=1,2, \ldots
$$

where,

$$
\begin{aligned}
& m_{1}=\sigma\left[\beta^{-1}+\frac{\left(1-\omega_{2}\right) \omega_{2}}{\kappa \delta}\right], \\
& m_{2}=\frac{\sigma\left[\beta^{-1}+\frac{(1-\rho)}{\kappa \delta}\right]}{\left(\omega_{1}-\rho\right)(\tau+\alpha)\left(1-\frac{\omega_{2}}{\rho}\right)}, \\
& m_{3}=\frac{\sigma\left[\beta^{-1}+\frac{\left(1-\omega_{2}\right)}{\kappa \delta}\right]}{\left(\omega_{1}-\rho\right)(\tau+\alpha)\left(1-\frac{\omega_{2}}{\rho}\right)}
\end{aligned}
$$

Suppose, like discretion, our objective is to implement optimal policy under commitment by the Taylor rule through matching the inflation rate. As a result, we equate equation (39) with equation (36) and calculate the corresponding inflation target as given below,

$$
\pi_{T+j}^{*}=\frac{m_{1}}{\chi_{\pi_{1}} z} \omega_{2}^{j-1} \phi_{1, T^{c}}+\left[\frac{m_{2} \rho^{j-1}-m_{3}\left(\frac{\omega_{2}}{\rho}\right)^{j}}{\chi_{\pi_{1}} z}\right] u_{T^{c}+1}, j=1,2, \ldots
$$

Note, the inflation target given in equation (40) matches the inflation rate obtained under commitment and the Taylor rule. Also note that, the inflation target given in equation (40) has endogenous persistence and exogenous persistence determined by $\omega_{2}$ and $\rho$, respectively. As a result, the inflation target given in equation (40) is not an $\operatorname{AR}(1)$ process - contradicting our assumption about the inflation target process made in equation (33). Hence, the above discussion shows that, unlike discretion, the Taylor rule given in equation (31) cannot implement commitment by optimally choosing an $\mathrm{AR}(1)$ inflation target in the presence of a cost channel.

\subsection{The T-only Policy}

The T-only policy is originally proposed by Chattopadhyay and Daniel (2018); while analyzing the optimal policies and their implementation by Taylor rule for the canonical model when cost channel is absent. Monetary authority under the T-only policy optimally 
chooses the exit date of the economy from the ZLB but follows discretion after the economy permanently exits the ZLB. Chattopadhyay and Daniel (2018) have shown that, (i) the Taylor rule given in equation (31) can fully implement the optimal policy under discretion, commitment and the T-only by optimally choosing an AR(1) inflation target, (ii) the Tonly policy in the absence of a cost channel is easily communicable and yields almost all the welfare gains as produced by the optimal policy under commitment and (iii) the optimal policy under commitment is the best a monetary authority could implement by the Taylor rule given in equation (31) by choosing the AR(1) inflation target optimally.

However, the results change significantly in the presence of a cost channel; as the presence of cost channel significantly impairs the ability of the Taylor rule to implement optimal policies. In this section we show that, unlike the canonical model, the T-only policy is the best a monetary authority can implement by the Taylor rule given in equation (31) in the presence of a cost channel by optimally choosing an AR(1) inflation target. The derivation of the T-only policy in the presence of a cost channel and its implementation by the Taylor rule is explained below.

The monetary authority under the T-only policy optimally chooses the exit date of the economy from the ZLB but follows discretion after the economy permanently exits the ZLB. Let us assume that, $T^{o}+1$ is the exit date of the economy from the ZLB under the T-only policy in the presence of a cost channel. Hence, the monetary authority under the T-only policy chooses, $T^{o}$ optimally to minimize the loss function given in equation (4). The process of optimization produces the optimal the output gap and the inflation rate under the T-only policy as given by equation (41) below when the economy is in the ZLB, i.e. for $t=1,2, \ldots, T^{o}$.

$$
Z_{t}=\Gamma_{t}^{o}+A^{-\left(T^{o}-t+1\right)} Z_{T^{o}+1}
$$

where,

$$
\Gamma_{t}^{o}=\sum_{k=t}^{T^{o}} A^{-(k-t+1)} a r_{k}^{n}-\sum_{k=t}^{T^{o}} A^{-(k-t+1)} c
$$

and,

$$
Z_{t}=\left(y_{t}, \pi_{t}\right)^{\prime}
$$

Since, monetary authority under the T-only policy follows discretion after the economy exits the ZLB; the post-exit output gap and inflation rate are given by the following 
equations,

$$
\begin{aligned}
y_{t} & =\frac{u_{t}}{\left[\sigma \chi\left(1+\frac{\beta}{\kappa \delta}\right)-1\right](\mu-\rho)} \\
\pi_{t} & =-\chi y_{t}, \text { for } t \geq T^{o}+1 \ldots
\end{aligned}
$$

Our analysis shows that, the T-only policy in the presence of a cost channel closely replicates the optimal policy under commitment, and yields almost all the welfare gains produced by commitment. ${ }^{21}$

Figure 4 plots the output gap, the inflation rate, the nominal interest rate and the real interest rate under commitment, and also under the T-only policy for $\delta=1$. We have also used the parameter reported in Table 1 and the demand shock with, $u_{1}=0.024$ and $\rho=0.9$ to generate Figure 4 .

Figure 4: The T-only Policy and Optimal Policy under Commitment
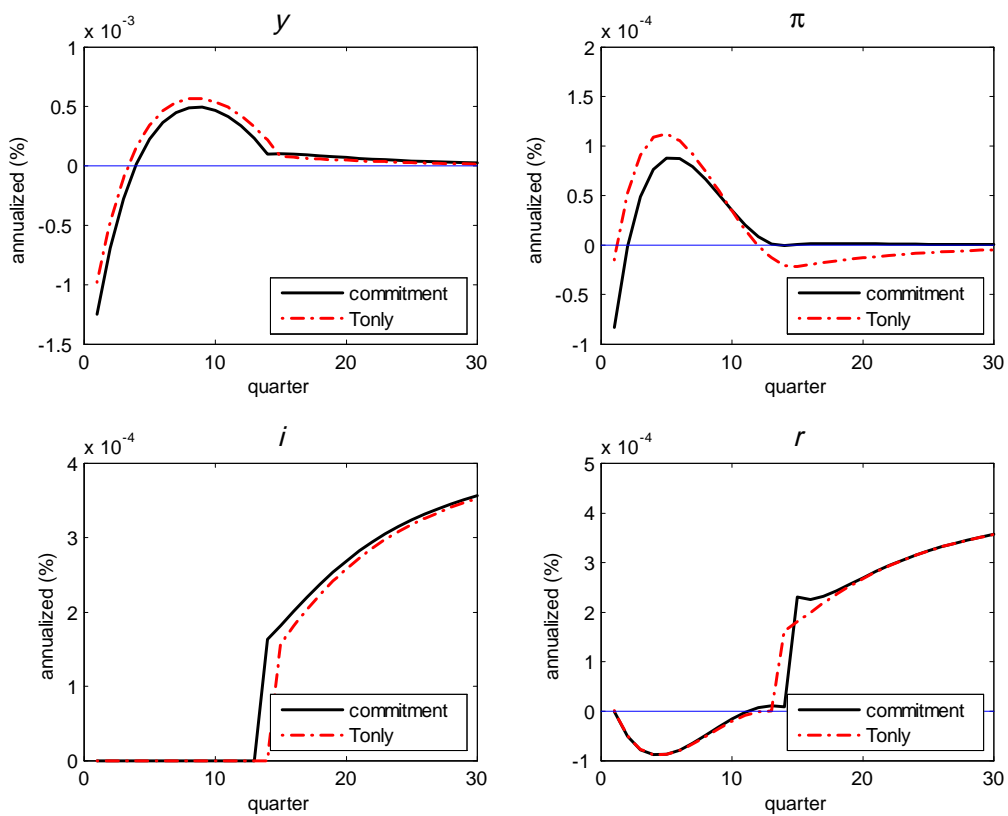

The T-only policy closely replicates the optimal policy under commitment and produces almost all the welfare gains producing by commitment.

\footnotetext{
${ }^{21}$ Similar result is obtained by Chattopadhyay and Daniel (2018) while analyzing optimal policies for the canonical model, when cost channel is absent.
} 
Figure 4 shows that, the T-only policy delays the exit date of the economy from the ZLB by a quarter compared to commitment, but otherwise replicates the optimal policy under commitment very closely. We find that the welfare loss under the T-only policy is only 1.28 times higher than that of commitment. To understand the implications of the differences in the exit date between the T-only policy and commitment note that, the economy under the T-only policy exits the ZLB with a deflation, and it also does not endogenize individual's expectations while minimizing the expected welfare loss. As a result, the T-only needs to generate additional stimulus to compensate the welfare loss (generated by the combination of the expected deflation and the exogenous individual's expectations) by postponing the exit date of the economy from the ZLB - allowing it to replicate commitment closely.

\subsection{Implementation of the T-only Policy}

Theorem 1 and Theorem 2 produces the third theorem of our paper; explaining the partial implementation of the T-only policy by the Taylor rule given in equation (31) under ZLB, and in the presence of a cost channel.

Theorem 3: In the presence of a cost channel, the Taylor rule with identical characteristics as stated in Theorem 1 partially implements the T-only policy when the economy is subject to zero lower bound. The T-only policy is the best that can be implemented under the Taylor rule with an optimally chosen AR(1) inflation target in the presence of a cost channel.

Proof: Points (i), (ii) and (iii) given below proves Theorem 3.

(i) The monetary authority under the T-only policy chooses the exit date of the economy from the ZLB optimally. However, the T-only policy follows discretion after the economy permanently exits the ZLB. Therefore, the characteristics of the T-only policy are identical with discretion, and it differs from discretion only in terms of the exit date of the economy from the ZLB. As a result, using Theorem 1 we can say that the T-only policy can be partially implemented by the Taylor rule given in equation (31) by optimally choosing an $\operatorname{AR}(1)$ inflation target.

(ii) Optimal policy under commitment always produces the lowest welfare loss by construction. However, Theorem 2 shows that commitment can not be implemented by the Taylor rule given in equation (31) through an optimally chosen AR(1) inflation target in the presence of a cost channel.

(iii) We find that, the welfare loss under the T-only policy on the other hand is lower 
than discretion but marginally higher than commitment. ${ }^{22}$ Moreover, we have already seen that, the T-only policy can be partially implemented by the Taylor rule given in equation (31) by an optimally chosen $\mathrm{AR}(1)$ inflation target. As a result, the T-only policy is the best that can be implemented by the Taylor rule in the presence of a cost channel when commitment is not implementable.

Figure 5: Implementing the T-only Policy by Taylor Rule
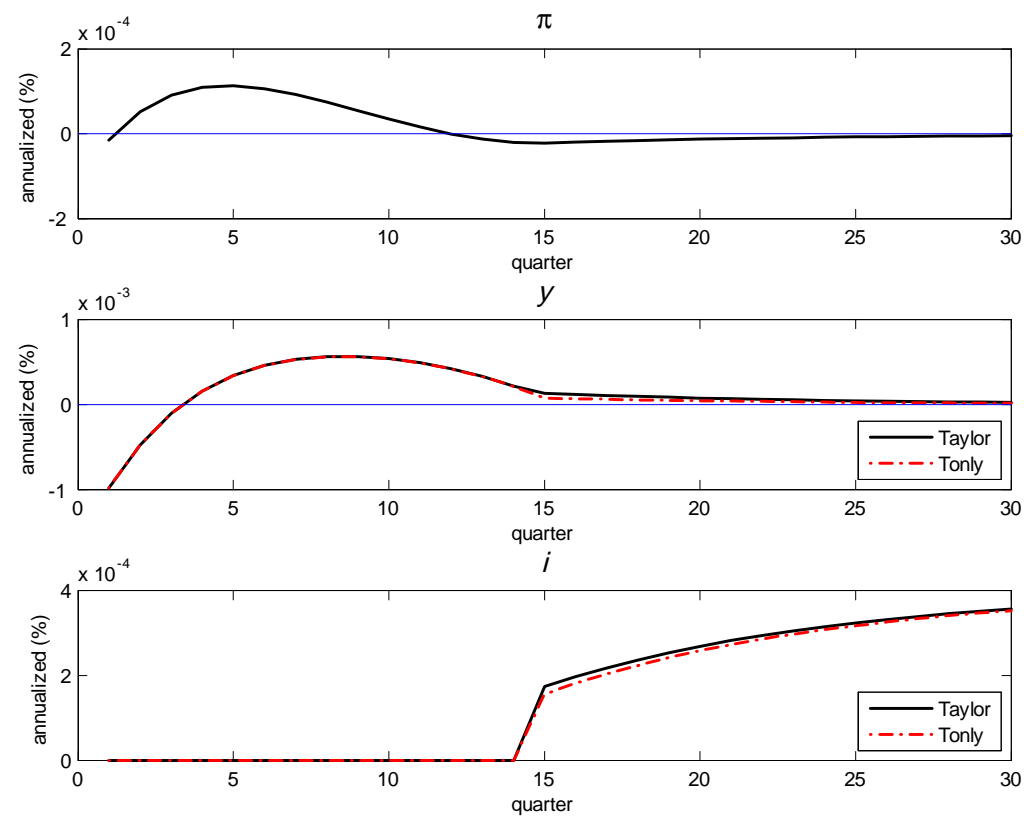

The T-only Policy implemented by Taylor rule through matching the inflation rate closely replicates the T-only policy itself, and producing almost identical welfare gains.

Figure 5 plots the actual T-only policy and the T-only policy implemented by the Taylor rule given in equation (31) through matching the inflation rate. We have used $\delta=1$ along with the parameter values reported in Table 1 and the demand shock with, $u_{1}=0.024$ and $\rho=0.9$ to generate Figure 5. The actual T-only policy and the T-only policy implemented by the Taylor rule through matching the inflation rate are very close to each

\footnotetext{
${ }^{22}$ We find that, the optimal discretionary policy produces 17.41 times higher welfare loss than that of commitment. On the other hand the T-only policy produces 1.28 times higher welfare loss than that of commitment under identical parameter values reported in Table 1 in the text, and with $\delta=1, u_{1}=0.024$ and $\rho_{u}=0.9$. This implies that, the welfare loss under discretion is 13.60 times higher than that of the T-only policy.
} 
other as shown in Figure 5. Our analysis shows that, the welfare loss of the T-only policy partially implemented by the Taylor rule through matching the inflation rate is only 1.004 times higher than that of the actual T-only policy itself. Moreover, we also find that, an initial inflation target, $\pi_{15}^{*}=0.000052$ with persistence, $\xi=0.9$ implements the T-only policy by the Taylor rule given in equation (31) through matching the inflation rate. Here, $T^{0}+1=15$ is the exit date of the economy from the ZLB under the T-only policy. Along with this, our analysis also shows that the T-only policy, partially implemented by the Taylor rule through matching the inflation rate closely replicates the optimal policy under commitment - as the former produces only 1.29 times higher welfare loss than that of the later.

\section{Issues Related to Uncertainty}

We have done our analysis under perfect foresight with a deterministic AR(1) demand shock. Hence, a natural concern would be whether our results holds under uncertainty as well. It is worth emphasizing that, the results obtained under perfect foresight as explained above holds for a certain type of uncertainty rule based on rational expectations with permanent exit of the economy from the ZLB. Chattopadhyay and Daniel (2018) have proposed such a kind of uncertainty rule while analyzing optimal policies for the canonical model. The uncertainty rule proposed by them has following two important properties, (i) uncertainty in the persistence of demand shock: initially its true value is unknown to the public but people realize its actual magnitude after certain period of time, but before the economy exits the ZLB, and (ii) the incidence of ZLB is persistent but non-recursive. This implies that, the economy can permanently exit the ZLB. ${ }^{23}$ Our results obtained under perfect foresight hold under the uncertainty rule proposed by Chattopadhyay and Daniel (2018). On the other hand, our results does not hold under an uncertainty rule that never allows the permanent exit of the economy from the ZLB, as used in Adam and Billi (2006, 2007) and Nakov (2008).

The uncertainty rule proposed by Chattopadhyay and Daniel (2018) has some practical implications as well. It is evident from history that, the incidence of ZLB episodes are indeed rare. The US was in the ZLB during the time of great depression in 1930. The incidence of ZLB recurred back only recently in the US, the UK and other developed countries during the time of global financial crisis at 2007-08. Keeping this low probability

\footnotetext{
${ }^{23}$ Chattopadhyay and Daniel (2018) have shown that, the (truncated) Taylor rule given in equation (31) fully implements the optimal policy under discretion, commitment and the T-only policy for the canonical model under perfect foresight, and also under the uncertainty rule proposed by them.
} 
of the ZLB incidence in mind, Chattopadhyay and Daniel (2018) have proposed their uncertainty rule (with two properties stated above) while analyzing the implementation of optimal policies by the Taylor rule for the canonical model.

Simple intuitive explanations is given below to show the Taylor rule implementation of the optimal discretionary policy under the uncertainty rule proposed by Chattopadhyay and Daniel (2018). The following discussion shows that, like perfect foresight, the Taylor rule given in equation (31) also partially implements the optimal discretionary policy under the uncertainty rule proposed by Chattopadhyay and Daniel (2018).

(I) Chattopadhyay and Daniel (2018) show that, the uncertainty rule proposed by them changes the exit date of the economy from the ZLB under the optimal discretionary policy. Suppose the exit date of the economy from the ZLB under perfect foresight and under uncertainty are given respectively by $T^{d}+1$ and $T^{d^{\prime}}+1$. Note, that changes in exit date causes the economy to exit the ZLB with different magnitudes of demand shock. Suppose, $u_{T^{d}+1}$ and $u_{T^{d^{\prime}}+1}$ are the demand shocks associated with the exit date $T^{d}+1$ and $T^{d^{\prime}}+1$, respectively. ${ }^{24}$ Different magnitudes of demand shock at the exit date, on the other hand, changes the output gap and the inflation rate from $Z_{T^{d+1}}=\left(y_{T+1}, \pi_{T+1}\right)^{\prime}$ to $Z_{T^{d^{\prime}}+1}=\left(y_{T^{d^{\prime}}+1}, \pi_{T^{d^{\prime}}+1}\right)^{\prime}$. Note, the changes in the output gap and the inflation rate along with the changes in the exit date affects the pre-exit output gap and inflation rate from equation (21). The pre-exit output gap and inflation rate thus obtained can be implemented by the (truncated) Taylor rule given in equation (31) (irrespective of the presence of a cost channel) by solving equations (1) and (3) simultaneously with nominal interest set to zero.

(II) The economy follows rational expectations after its permanent exit from the ZLB, i.e., from $T^{d^{\prime}}+1$ onwards. Note that, the post-exit output gap given in equation (15) will be associated with sunspots under uncertainty. As a result, we need an unstable root, $\mu>1$ to get a sunspot free determinate solution of the output gap. The parametric restriction, $\delta \in[1,1.8]$, producing, $\mu>1$ yields identical solution of the output gap and the inflation rate as given in equations (17) and (18) respectively under the rational expectation. Moreover, note that the rational expectations solution of the output gap given in equation (35) and the inflation rate given in equation (36), obtained by solving equations (1) and (3) simultaneously under the Taylor rule given in equation (32) also remain unaltered after the economy permanently exits the ZLB.

(III) Then, the optimal inflation target, $\pi_{T^{d^{\prime}+1}}^{*}$ associated with the demand shock

${ }^{24}$ Note, we have $u_{T^{d}+1} \gtrless u_{T^{d^{\prime}}+1}$ when $T^{d}+1 \gtrless T^{d^{\prime}}+1$ and $u_{T^{d}+1}=u_{T^{d^{\prime}}+1}$ when $T^{d}+1=T^{d^{\prime}}+1$. 
$u_{T^{d^{\prime}+1}}$ is chosen from equation (37) by matching the inflation rate produced by the optimal discretionary policy with same produced by the Taylor rule. The inflation target and the demand shock subsequently follow the deterministic $\mathrm{AR}(1)$ process with persistence, $\xi=\rho$.

Note, we have already seen that the Taylor rule given in equation (31) partially implements the optimal discretionary policy under perfect foresight by matching the inflation rate. Points (I), (II) and (III) together imply that the same Taylor rule also partially implements the optimal discretionary policy by matching the inflation rate under the uncertainty rule proposed by Chattopadhyay and Daniel (2018).

Similarly, we can show that the Taylor rule given in equation (31) with optimally chosen $\mathrm{AR}(1)$ inflation target partially implements the T-only policy but cannot implement commitment under the uncertainty rule proposed by Chattopadhyay and Daniel (2018) the results obtained under perfect foresight.

Note, above discussion shows that, the uncertainty does affect the dynamics of the system significantly compared to perfect foresight. It is important to note in this context that, the objective of our paper is to examine the implementation of optimal policies by the Taylor rule, and not to analyze the properties of business cycle under uncertainty with perfect foresight in the presence of a cost channel. Therefore, after deriving optimal policies and analyzing its Taylor rule implementation under perfect foresight with a deterministic AR(1) demand shock; we have given a simple intuitive explanations (instead of any complicated mathematical derivation) to establish our results regarding the Taylor rule implementations of the optimal policies under uncertainty in the presence of a cost channel.

\section{Conclusion}

Implementation of optimal policies are as important as prescribing them in the first place. Chattopadhyay and Daniel (2018) have analyzed the implementation of optimal policies for the canonical New-Keynesian DSGE model by the Taylor rule at the ZLB. They found that, the optimal discretionary policy, optimal policy under commitment and the T-only policy can be implemented by the Taylor rule for a canonical model at the ZLB. We have analyzed the implementation of the optimal discretionary policy, optimal policy under commitment and the T-only policy for a New-Keynesian DSGE model with cost channel developed by Ravenna and Walsh (2006) using an identical Taylor rule.

We find that, the short-run trade-off between the output gap and the inflation rate 
introduced by the endogenous cost push shock produces meaningful policy responses for the model with cost channel, but at the same time it also significantly impairs the ability of the Taylor rule to implement the optimal policies. Our analysis shows that, the Taylor rule with optimally chosen $\mathrm{AR}(1)$ inflation target partially implements the optimal discretionary policy by matching the inflation rate in the presence of a cost channel. Our analysis also shows that, the optimal policy under commitment in the presence of a cost channel cannot be implemented and therefore, the T-only policy is the best that can be implemented by the Taylor rule with optimally chosen $\operatorname{AR}(1)$ inflation target in the presence of a cost channel. We find that the T-only policy, partially implemented by the Taylor rule through matching the inflation rate closely replicates the optimal policy under commitment in the presence of a cost channel, and yields almost all the welfare gains produced by commitment. Therefore, our analysis finds that the cost channel does matter for implementing optimal policies by the Taylor rule and its presence should be carefully analyzed while implementing optimal policies.

\section{Appendix}

\section{1 post-exit Solution of the Optimal Policy under Commitment}

The complementary slackness condition given in the text implies, $i_{t}>0$ when, $Q_{t}^{c}=0$ for $t=T^{c}+1, T^{c}+2, \ldots$. Therefore, equation (26) this implies,

$$
\phi_{2, t}=\frac{\sigma}{\kappa \delta} \phi_{1, t}
$$

Equations (22) and (23) with equation (42) gives,

$$
\pi_{t}=-\frac{\sigma}{\kappa \delta} \phi_{1, t}+\sigma\left(\beta^{-1}+\frac{1}{\delta \kappa}\right) \phi_{1, t-1}
$$

and,

$$
y_{t}=-\lambda^{-1}\left(1-\left(\sigma^{-1}+\eta\right) \frac{\sigma}{\delta}\right) \phi_{1, t}+\lambda^{-1} \beta^{-1} \phi_{1, t-1}
$$

By eliminating $i_{t}$ from equations (24) and (25) we have,

$$
y_{t+1}+\sigma\left(1+\frac{\beta}{\kappa \delta}\right) \pi_{t+1}=\left[1-\frac{\sigma^{-1}+\eta}{\sigma^{-1} \delta}\right] y_{t}+\frac{\sigma}{\kappa \delta} \pi_{t}+u_{t}
$$


Combining equations (43), (44) and (45) gives the following second order difference equation for $\phi_{1, t}$,

$$
\phi_{1, t+1}=b_{1} \phi_{1, t}+b_{2} \phi_{1, t-1}+b_{3} u_{t}
$$

where

$$
b_{1}=\frac{\beta^{-1} \tau^{2} \vartheta^{-1}+\lambda^{-1} \beta^{-1}+\vartheta+\alpha^{2} \lambda}{\tau+\alpha}, b_{2}=-\beta^{-1}, b_{3}=-(\tau+\alpha)^{-1}
$$

and

$$
\tau=\frac{\sigma^{2}}{\kappa \delta}\left[1+\frac{\beta}{\kappa \delta}\right], \alpha=\left[1-\left(\sigma^{-1}+\eta\right) \frac{\sigma}{\delta}\right] \lambda^{-1}, \vartheta=\frac{\sigma^{2}}{\kappa^{2} \delta^{2}}
$$

To solve the difference equation we assume, $\gamma_{t+1}=\phi_{1, t}$. This allows me to rewrite the equation (46) as,

$$
\psi_{t+2}=B \psi_{t+1}+b u_{t+1}
$$

where,

$$
\psi_{t+2}=\left[\begin{array}{c}
\phi_{1, t+2} \\
\gamma_{t+2}
\end{array}\right], B=\left[\begin{array}{cc}
b_{1} & b_{2} \\
1 & 0
\end{array}\right], b=\left[\begin{array}{c}
b_{3} \\
1
\end{array}\right]
$$

Let, $\omega_{1}$ and $\omega_{2}$ be the two eigenvalues of $B$ such that $\omega_{1}>1$ and $0<\omega_{2}<1$. Suppose, $\Omega$ is the matrix of eigenvalues and $E$ is the matrix of eigenvector of $B$.

$$
\Omega=\left[\begin{array}{cc}
\omega_{1} & 0 \\
0 & \omega_{2}
\end{array}\right], E=\left[\begin{array}{cc}
\omega_{1} & \omega_{2} \\
1 & 1
\end{array}\right]
$$

Diagonalization of $B$ gives,

$$
\psi_{t+2}^{\prime}=\Omega \psi_{t+1}^{\prime}+E^{-1} b u_{t+1}
$$

where, $\psi_{t+2}^{\prime}=E^{-1} \psi_{t+2}$.

Solving the first equation (47) forward and second equation of (47) backward gives,

$$
\begin{aligned}
\phi_{1, t} & =\omega_{2} \phi_{1, t-1}+\frac{u_{t}}{\left(\omega_{1}-\rho\right)(\tau+\alpha)} \\
\phi_{2, t} & =\frac{\sigma}{\kappa \delta} \phi_{1, t}
\end{aligned}
$$

Note, equations (22) and (23) in the text gives,

$$
\Phi_{t}=C \Phi_{t-1}-D Z_{t}
$$


where,

$$
\begin{aligned}
\Phi_{t} & =\left[\begin{array}{l}
\phi_{1, t} \\
\phi_{2, t}
\end{array}\right], Z_{t}=\left[\begin{array}{l}
y_{t} \\
\pi_{t}
\end{array}\right], D=\left[\begin{array}{cc}
\lambda & \kappa\left(\sigma^{-1}+\eta\right) \\
0 & 1
\end{array}\right] \\
C & =\left[\begin{array}{cc}
\beta^{-1}+\frac{\sigma \kappa\left(\sigma^{-1}+\eta\right)}{\beta} & \kappa\left(\sigma^{-1}+\eta\right) \\
\frac{\sigma}{\beta} & 1
\end{array}\right]
\end{aligned}
$$

Forward solution of equation (49) with, $\Phi_{1}=0$ and using equation (30) gives,

$$
\begin{aligned}
\Phi_{T^{c}} & =-\sum_{t=1}^{T^{c}} C^{\left(T^{c}-t\right)} D Z_{t} \\
& =-\sum_{t=1}^{T^{c}} C^{\left(T^{c}-t\right)} D\left(\Gamma_{t}^{c}+A^{-\left(T^{c}-t+1\right)} Z_{T^{c}+1}\right)
\end{aligned}
$$

Now, equations (43), (44) along with equation (48) gives,

$$
Z_{T^{c}+1}=\Theta \Phi_{T^{c}}+J u_{T^{c}+1}
$$

where,

$$
\begin{aligned}
& \Theta=\left[\begin{array}{cc}
\lambda^{-1}\left[\beta^{-1}-\omega_{2}\left\{1-\left(\sigma^{-1}+\eta\right) \frac{\sigma}{\delta}\right\}\right] & 0 \\
\beta^{-1}+\frac{1-\omega_{2}}{\kappa \delta} & 0
\end{array}\right] \\
& J=\left[\begin{array}{cc}
\frac{-\lambda^{-1}\left[1-\left(\sigma^{-1}+\eta\right) \frac{\sigma}{\delta}\right]}{\left(\omega_{1}-\rho\right)(\tau+\alpha)} \\
\frac{\sigma}{\kappa \delta\left(\omega_{1}-\rho\right)(\tau+\alpha)}
\end{array}\right]
\end{aligned}
$$

Then by substituting equation (51) to equation (50) we get,

$$
\Phi_{T^{c}}=-W_{1}^{-1} W_{2}
$$

where,

$$
\begin{aligned}
& W_{1}=I+\sum_{t=1}^{T^{c}} C^{\left(T^{c}-t\right)} D A^{-\left(T^{c}-t+1\right)} \Theta \\
& W_{2}=\sum_{t=1}^{T^{c}} C^{\left(T^{c}-t\right)} D\left[\Gamma_{t}^{c}+A^{-\left(T^{c}-t+1\right)} J u_{T+1}\right]
\end{aligned}
$$


Equation (52) solves $T^{c}$ such that $Q_{T^{c}}=\sigma \phi_{1, T^{c}}-\kappa \delta \phi_{2, T^{c}}>0$ for the last time and also $\Phi_{T^{c}}$. Next, equation (48) solves $\phi_{1, t}$ and equation (43), (44) solve $y_{t}$ and $\pi_{t}$.

\subsection{Solution under Taylor Rule}

This section provides the solution of the output gap and the inflation rate under the Taylor rule. Substituting equation (32) in equation (3) and using equation (33) we get,

$$
y_{t}^{*}=\left[\frac{1-(\beta+\kappa \delta) \xi}{\kappa\left(\sigma^{-1}+\eta\right)}\right] \pi_{t}^{*}+\left[\frac{\delta}{\left(\sigma^{-1}+\eta\right)}\right] u_{t},
$$

Subsequently, substituting equations (53) and (33) in equation (32) gives,

$$
i_{t}=r_{t}^{n}+\phi_{\pi} \pi_{t}+\phi_{y} y_{t}-z \pi_{t}^{*}-\left[1+\frac{\phi_{y} \delta}{\left(\sigma^{-1}+\eta\right)}\right] \sigma^{-1} u_{t}
$$

where,

$$
z=\phi_{\pi}+\phi_{y}\left[\frac{1-(\beta+\kappa \delta) \xi}{\kappa\left(\sigma^{-1}+\eta\right)}-\xi\right]
$$

Solving equations (1), (3) and (54) simultaneously we get,

$$
E_{t}\left(X_{t+1}\right)=A X_{t}+\Gamma \epsilon_{t}
$$

where,

$$
\begin{aligned}
X_{t}=\left(\begin{array}{ll}
y_{t} & \pi_{t}
\end{array}\right)^{\prime}, \epsilon_{t}=\left(\begin{array}{ll}
z \pi_{t}^{*} & u_{t}
\end{array}\right)^{\prime} \\
A=\left(\begin{array}{ll}
a_{11} & a_{12} \\
a_{21} & a_{22}
\end{array}\right), \Gamma=\left(\begin{array}{ll}
\gamma_{11} & \gamma_{12} \\
\gamma_{21} & \gamma_{22}
\end{array}\right) \\
a_{11}=1+\sigma\left[\phi_{y}\left(1+\frac{\kappa \delta}{\beta}\right)+\left(\frac{\kappa\left(\sigma^{-1}+\eta\right)}{\beta}\right)\right], \\
a_{12}=\phi_{\pi}\left(1+\frac{\kappa \delta}{\beta}\right)-\frac{1}{\beta}, \\
a_{21}=-\frac{\kappa}{\beta}\left(\sigma^{-1}+\eta+\delta \phi_{y}\right), \\
a_{22}=\frac{1-\kappa \delta \phi_{\pi}}{\beta}
\end{aligned}
$$




$$
\begin{aligned}
\gamma_{11} & =-\sigma\left(1+\frac{\kappa \delta}{\beta}\right) \\
\gamma_{12} & =-\delta\left[\frac{\kappa}{\beta}+\frac{\phi_{y}}{\sigma^{-1}+\eta}\left(1+\frac{\kappa \delta}{\beta}\right)\right], \\
\gamma_{21} & =\frac{\kappa \delta}{\beta} \\
\gamma_{22} & =\frac{\kappa \delta}{\sigma \beta}\left(1+\frac{\phi_{y} \delta}{\sigma^{-1}+\eta}\right)
\end{aligned}
$$

Also assume that,

$$
\Gamma^{-1}=\left(\begin{array}{ll}
\gamma^{11} & \gamma^{12} \\
\gamma^{21} & \gamma^{22}
\end{array}\right)
$$

Note, both the output gap and the inflation rate given in equation (56) are associated with sunspots. Sunspot free determinate equilibrium requires both eigenvalues of matrix, $A$ to be greater than one. The condition for which both eigenvalues of matrix $A$ are greater than one is given below. Suppose, two eigenvalues of matrix, $A$ are, $\lambda_{1}$ and $\lambda_{2}$, $\lambda_{1}>\lambda_{2}$.

The characteristic equation with both eigenvalues greater one gives,

$$
|A|+\operatorname{tr}(A)+1>0
$$

The determinant of matrix, $A$ is,

$$
|A|=\frac{1}{\beta}-\frac{\kappa \delta \phi_{\pi}}{\beta}+\frac{\sigma \phi_{y}}{\beta}+\frac{\kappa\left(\sigma^{-1}+\eta\right) \sigma \phi_{\pi}}{\beta}
$$

Substituting, $|A|$ and trace of matrix, $A, \operatorname{tr}(A)$ to equation (57) gives,

$$
\phi_{\pi}+\frac{1-(\beta+\kappa \delta)}{\kappa\left(\sigma^{-1}+\eta\right)} \phi_{y}>1
$$

Equation (58) is the condition of Taylor principle in the presence of a cost channel. We have chosen our parameter values given in the text so that equation (58) is satisfied and produces sunspot free determinate equilibrium. ${ }^{25}$ Note, we get the Taylor principle for the canonical model given by Bullard and Mitra (2002) back when, $\delta=0$. Also note that, $z$ given in equation (55) is positive when the Taylor principle given in equation (58) is satisfied. We find that, Taylor principle given in equation (58) is satisfied when, $\phi_{\pi}>1$

\footnotetext{
${ }^{25}$ Also see, Smith (2016) and Llosa and Tuesta (2009) respectively for a discussion on equilibrium determinacy and E-stability of the model under learning in the presence of a cost channel.
} 
and $0<\phi_{y}<1$ and $\delta=1$.

Solving system (56) forward gives,

$$
\begin{aligned}
& y_{t}=\chi_{y_{1}} z \pi_{t}^{*}+\chi_{y_{2}} u_{t}, \\
& \pi_{t}=\chi_{\pi_{1}} z \pi_{t}^{*}+\chi_{\pi_{2}} u_{t}
\end{aligned}
$$

where,

$$
\begin{aligned}
& \chi_{y_{1}}=-\left[\left(\frac{\lambda_{1}-a_{22}}{a_{21}}\right)\left(\frac{\gamma^{11} \lambda_{1}}{\lambda_{1}-\xi}\right)+\left(\frac{\lambda_{2}-a_{22}}{a_{21}}\right)\left(\frac{\gamma^{21} \lambda_{2}}{\lambda_{2}-\xi}\right)\right], \\
& \chi_{y_{2}}=-\left[\left(\frac{\lambda_{1}-a_{22}}{a_{21}}\right)\left(\frac{\gamma^{12} \lambda_{1}}{\lambda_{1}-\rho}\right)+\left(\frac{\lambda_{2}-a_{22}}{a_{21}}\right)\left(\frac{\gamma^{22} \lambda_{2}}{\lambda_{2}-\rho}\right)\right], \\
& \chi_{\pi_{1}}=-\left[\left(\frac{\lambda_{1} \gamma^{11}}{\lambda_{1}-\xi}+\frac{\lambda_{2} \gamma^{21}}{\lambda_{2}-\xi}\right)\right], \\
& \chi_{\pi_{2}}=-\left[\left(\frac{\lambda_{1} \gamma^{12}}{\lambda_{1}-\rho}+\frac{\lambda_{2} \gamma^{22}}{\lambda_{2}-\rho}\right)\right]
\end{aligned}
$$

\section{References}

[1] Adam, K. and R. M. Billi (2006), Optimal Monetary Policy under Commitment with a Zero Bound on Nominal Interest Rates, Journal of Money, Credit, and Banking 39(7), 1877-1905.

[2] Adam, K. and R. M. Billi (2007), Discretionary Monetary Policy and the Zero Lower Bound on Nominal Interest Rates, Journal of Monetary Economics 54(3), 728-52.

[3] Ali, Z. S. and S. Anwar (2013), Inflation and Interest Rates, in The Presence of A Cost Channel, Wealth Effect and Agent Heterogeneity, Economic Modelling, 31, 286-96.

[4] Araujo, E. (2009), Supply Side Effects of Monetary Policy and the Central Bank's Objective Function, Economics Bulletin, 29(2), 680-92.

[5] Barth, M. J. and V. A. Ramey (2001), The Cost Channel of Monetary Transmission (in Bernanke, B. and K. Rogoff ed.), NBER Macroeconomics Annual, 16, 199-240.

[6] Bullard, J. and K. Mitra, (2002), Learning about Monetary Policy Rules, Journal of Monetary Economics, 63(3), 477-96. 
[7] Chattopadhyay, S. and B. C. Daniel (2018), Taylor-Rule Exit Policies for the Zero Lower Bound, International Journal of Central Banking, 14(5), 1-52.

[8] Chowdhury, I., M. Hoffman and A. Schabert (2006), Inflation Dynamics and the Cost Channel of Monetary Transmission, European Economic Review 50(4), 995-1016.

[9] Christiano, L., J. M. Eichenbaum and C. L. Evans (2005), Nominal Rigidities and the Dynamic Effects of a Shock to Monetary Policy, Journal of Political Economy $113(1), 1-45$.

[10] Demirel, U. D. (2013), Gains from Commitment in Monetary Policy: Implications of The Cost Channel, Journal of Macroeconomics, 38(Part B), 218-26.

[11] Eggertsson, G. and M. Woodford (2003), The Zero Bound on Interest Rates and Optimal Monetary Policy, Brookings Paper on Economic Activity, 1, 139-211.

[12] Eggertsson, G. B. and M. Woodford (2004), Policy Options in a Liquidity Trap, American Economic Review 94(2),76-79.

[13] Gurkaynak, R. S., B. Sack and E. Swanson (2005), The Excess Sensitivity of LongTerm Interest Rate to Economic News: Evidence and Implications for Macroeconomic Models, American Economic Review, 95(1), 425-36.

[14] Henzel S. O., E. Hülsewig, T. Mayer and T. Wollmershäuser (2009), The Price Puzzle Revisited: Can The Cost Channel Explain a Rise in Inflation after A Monetary Policy Shock? Journal of Macroeconomics 31(2), 268-289.

[15] Ireland, P. N. (2007), Changes in the Federal Reserve's Inflation Target: Causes and Consequences, Journal of Money, Credit and Banking, 39(8), 1851-82.

[16] Jung, T., Y. Teranishi, and T. Watanabe (2005), Optimal Monetary Policy at the Zero-Interest-Rate Bound, Journal of Money, Credit, and Banking 37(5), 813-835.

[17] Kozicki, S. and P.A. Tinsley (2001), Shifting Endpoints in the Term Structure of Interest Rates, Journal of Monetary Economics 47(3), 613-652.

[18] Llosa, L. and V. Tuesta (2009), Learning About Monetary Policy Rules when CostChannel Matters, Journal of Economic Dynamics and Control, 33(11), 1880-96.

[19] Nakov, A. (2008), Optimal and Simple Monetary Policy Rules with Zero Floor on the Nominal Interest Rate, International Journal of Central Banking, 4(2), 73-128. 
[20] Pathberiyay, L. R. C. (2016), Optimal Monetary Policy at the Zero Lower Bound on Nominal Interest Rates in a Cost Channel Economy, The University of Queensland, School of Economics Discussion Paper Series no. 568.

[21] Rabanal, P. (2007), Does Inflation Increase After a Monetary Policy Tightening? Answers Based on An Estimated DSGE Model, Journal of Economic Dynamics and Control, 31(3), 906-37.

[22] Ravenna, F. and C. E. Walsh (2006), Optimal Monetary Policy with the Cost Channel, Journal of Monetary Economics 53(2), 199-216.

[23] Smith, A. L. (2016), When Does the Cost Channel Pose a Challenge to Inflation Targeting, European Economic Review, 89, 471-94.

[24] Tillmann, P. (2008), Do Interest Rates Drive Inflation Dynamics? An Analysis of the Cost Channel of Monetary Transmission, Journal of Economic Dynamics and Control 32(9), 2723-44.

[25] Tillmann, P. (2009a), The Time-Varying Cost Channel of Monetary Transmission, Journal of International Money and Finance 28(6), 941-53.

[26] Tillmann, P. (2009b), Optimal Monetary Policy with an Uncertain Cost Channel, Journal of Money, Credit and Banking, 41(5), 885-906.

[27] Woodford, M. (2003), Interest and Prices: Foundations of a Theory of Monetary Economics, Princeton University Press, Princeton and Oxford.

[28] Wu, T. and G. Rudebusch (2004), The Recent Shift in Term Structure Behavior from a No-Arbitrage Macro-Finance Perspective, Federal Reserve Bank of San Francisco. 